\title{
Effects of 660 nm Low Level Laser Therapy on Neuropathic Pain Relief Following Chronic Constriction Injury in Rat Sciatic Nerve
}

\author{
Masoume Masoumipoor ${ }^{1}$, Seyed Behnam Jameie ${ }^{1,2,3, *}$, Atusa Janzadeh ${ }^{2,4}$, Farinaz \\ Nasirinezhad $^{4,5}$, Mahdie Kerdari $^{2}$, Maryam Soleimani ${ }^{3}$ \\ ${ }^{1}$ Department of Nuclear Engineering, Islamic Azad University, Tehran, IR Iran \\ ${ }_{3}^{2}$ Department of Medical Basic Sciences, Iran University of Medical Sciences, Tehran, IR Iran \\ 3 Department of Anatomy, Iran University of Medical Sciences, Tehran, IR Iran \\ ${ }^{4}$ Research Center of Physiology, Iran University of Medical Sciences, Tehran, IR Iran \\ 5 Department of Physiology, Iran University of Medical Sciences, Tehran, IR Iran \\ *Corresponding author: Seyed Behnam Jameie, Department of Medical Basic Sciences, Iran University of Medical Sciences, Tehran, IR Iran. Tel.: +98-2186704529, Fax: +98-2188622694, \\ E-mail: behnamjameie@tums.ac.ir.
}

Received: July 22, 2013; Accepted: September 9, 2013

Background: Different types of pain such as neuropathic pain (NP) are still challengeable conditions in medical disciplines. Neuropathy leads to medical, social and economic problems for the patient, thus various therapies are being used to treat or reduce it. There are numerous studies mainly focused on the role of reactive oxygen species (ROS) and oxidative stress for NP. Recently, Low level Laser Therapy (LLLT) has been used in certain areas of medicine and neuro-rehabilitation. Chronic constriction injury (CCI) is a well-known model for neuropathic pain studies.

Objectives: The present research was designed to find the effects of 660 wave length LLLT on injured sciatic nerve.

Materials and Methods: Twenty Wistar adult male rats $(230-320 \mathrm{~g})$ were used in this study. The animals were randomly divided into three groups $(n=10)$. To induce neuropathic pain for sciatic nerve, CCI technique was used. Low Level Laser of 660nm was used for consecutive two weeks. Thermal and mechanical hyperalgesia were performed before and after the operation on days 7 and 14 respectively. Paw withdrawal thresholds were also evaluated.

Results: Our results showed that CCI decreased the pain threshold; whereas, LLLT of 660nm wave length for two weeks increased the mechanical and thermal thresholds significantly. Comparison of the mechanical and thermal thresholds showed significant therapeutic effects of LLLT in trial groups than control.

Conclusions: Although our results showed the therapeutic effects of LLLT on NP and might be used for clinical application in neuropathic cases; more future clinical studies are needed.

Keywords: Laser Therapy, Low-Level; Chronic Constriction Injury; Neuralgia

\section{Background}

Pain classically defined as an unpleasant sensory and emotional experience which is usually associated with tissue damage (1). Two clinical types of pain including acute and chronic are reported, the former one is a protective mechanism which alerts the individual to certain condition that is immediately harmful to the body; whereas, the chronic pain is persistent or intermittent. Acute pain rarely needs medical attention; when it does, nonsteroidal anti-inflammatory drugs (NSAIDs), powerful opioid analgesics, or local anesthetics can adequately control the pain. Chronic pain differs from acute pain not only due to its onset and duration, but more importantly in its mechanisms. Chronic pain may not have identifiable ongoing injury or inflammation, and often responds poorly to NSAIDs and opioids (2). Neuropathic pain (NP) known as a form of chronic pain results from any kind of damage to the central or peripheral nervous system $(3,4)$. Patients with NP often have spontaneous pain, allodynia, and hyperalgesia. NP may have delayed onset after initial nerve injury; therefore, pain may be present in the absence of apparent lesion or injury, making proper diagnosis and early treatment difficult $(5,6)$. The chronic constriction injury (CCI) model, developed by Bennett and $\mathrm{Xie}$, is a well-known model of mononeuropathy which produces signs of NP (7). The CCI shows inflammatory characterization related to the condition/disease and is reported that the inflammatory component of NP in the case of $\mathrm{CCI}$ is present mainly in the first phase of the disease (8). Mechanical test of paw withdrawal latencies and observations of guarding behavior to certain mechanical

Implication for health policy/practice/research/medical education:

Our data significantly confirmed the therapeutic effects of LLLT on pain reduction in neuropathic pain; the wavelength of 660 nm was effective. In discussion we discuss the mechanisms of LLLT effectiveness on pain reduction. The significance of this study is to provide new ways in laser therapy for clinical trials to reduce certain type of pain in patients with peripheral nerve injuries.

Copyright (C) 2014, Tehran University of Medical Sciences. This is an open-access article distributed under the terms of the Creative Commons Attribution License, which permits unrestricted use, distribution, and reproduction in any medium, provided the original work is properly cited. 
stimuli and thermal stimulation including the tail flick test (9), the hind limb withdrawal plantar test (10), and the hotplate test $(11,12)$ have been extensively used in assessing pain behavior in animals $(13,14)$. Certain types of therapy including prescription of analgesic drugs, electrical stimulation, and ultrasound and laser therapy have been developed during the recent years to decrease the regenerative process and return the function (15). LLLT is a special type of laser therapy in which the irradiation used is red or near infrared beams with a wavelength of 600 - $1100 \mathrm{~nm}$ and an output power of $1-500 \mathrm{~mW}$. This type of radiation is a continuous wave or pulsed light which consists of a constant beam of relatively low energy density $\left(0.04-50 \mathrm{~J} / \mathrm{cm}^{2}\right)(16,17)$. Since 1970s LLLT has been used in several clinical and experimental research studies on peripheral nerve injuries. Irradiation parameters and properties of LLLT, such as dose, intensity, time and application methods are notably varied among different clinical reports. The clinical effects of LLLT including cell apoptosis, improving cell proliferation, migration, cell adhesion, enhancing the cells' mitotic activity, increasing blood flow, and local microcirculation are reported in many studies (18). Reis et al. reported effectiveness of laser at $660 \mathrm{~nm}$ for recovery of sciatic nerve in rat model following neurotmesis (19). Belchior et al. reported clinical and functional recovery of injured sciatic nerve by using GaAlAs laser at a wavelength of $660 \mathrm{~nm}$, density of $4 \mathrm{~J} / \mathrm{cm}^{2}$ for 21 days consecutively. It is also reported that the use of low level laser (660 nm) could significantly promote neural regeneration (20). Barbosa et al. used laser at $660 \mathrm{~nm}$ and $830 \mathrm{~nm}$ for recovery of sciatic nerve regeneration following crushing injuries, and reported that $660 \mathrm{~nm}$ provided early functional nerve recovery in comparison to $830 \mathrm{~nm}$ (21). Hsieh et al. demonstrated that $660 \mathrm{~nm}$ GaAlAs laser at a dose of $9 \mathrm{~J} / \mathrm{cm} 2$ significantly reduced neuropathic allodynia in rats with CCI and significantly promoted functional recovery (22), Bertolini et al. also reported the same results (23).

\section{Objectives}

The controversy on energy densities and wavelengths of LLLT for peripheral neuropathies and the lack of specific pain evaluation among different studies led us to design the present research.

\section{Materials and Methods}

\subsection{Animals}

Twenty adult male Wistar rats (250 - $320 \mathrm{~g}$ ) were used in this study. The animals were divided into three groups ( $\mathrm{n}$ $=10$ ) as follows:

-CCI group: animals that were subjected to surgical procedure, without undergoing irradiation.

-CCI + Laser 660nm therapy group (LLLT $660 \mathrm{~nm}$ ): animals that were subjected to surgical procedure and also received laser irradiation with energy density of $4 \mathrm{~J} / \mathrm{cm}^{2}$ and intensity of $0.354\left(\mathrm{~W} / \mathrm{cm}^{2}\right)$

-Control group: self-control

Animals received food and water ad libitum, and all procedures were performed according to the Ethic Committee for Animal Research of IUMS. All the animals were subjected to the functional evaluation before the operation (self-control). To induce neuropathic pain, the sciatic nerve injury model described by Bennett and Xie was used which is explained elsewhere (7).

\subsection{Laser Therapy}

A couple of CW diode lasers emitter with following specification were used in this study. A laser with the wavelength of $660 \mathrm{~nm}$, the power of $100 \mathrm{~mW}$ (Heltschl; model: ME-TL10000-SK), the energy density of $4 \mathrm{~J} / \mathrm{cm}^{2}$, and the power density of $0.354 \mathrm{~W} / \mathrm{cm}^{2}$. Calibration was performed before use. Three points of the surgical incision were irradiated transcutaneously with no direct skin contact as follows: two points on two ends of surgical incision, and another at the midpoint of them. The laser therapy was started on the first day after the operation and was continued for two weeks daily in same time between 10 - $12 \mathrm{AM}$.

\subsection{Functional Analysis}

\subsubsection{Thermal Withdrawal Threshold}

By using a Plantar Test apparatus (UgoBasile, Italy) thermal hyperalgesia, the latency to withdrawal of the hind paws from a focused beam of radiant heat applied to the plantar surface, was studied (10). The animals were placed in an acrylic box with glass floor and the plantar surface of their hind paw was exposed to a beam of infrared radiant heat. The paw withdrawal latencies were recorded at infrared intensity of 50, and three trials for the right hind paws were performed and for each reading, the apparatus was set at a cut-off time of 25s. Each trial was separated by an interval time of 5 minutes.

\subsubsection{Mechanical Withdrawal Threshold}

Mechanical paw withdrawal thresholds were assessed with the Randall-Selitto method by using an Analgesymeter apparatus (UgoBasile, Italy (24)). This instrument exerts a force that increases at a constant rate. The force was applied to the hind paw of the rat, which was placed on a small plinth under a cone shaped pusher with a rounded tip (1.5 $\mathrm{mm}$ in diameter).The rat was held upright with the head and limb to be tested free, but most of the rest of the body cradled in the hands of the experimenter. The paw was then put under the pusher until the rat withdrew the hind paw was occurred. Each hind paw was tested twice, with a 10 min interval between the measurements, and mechanical paw withdrawal thresholds 
were calculated as the average of two consecutive measurements.

\subsection{Statistical Analysis}

Statistical analysis was performed using SPSS 19.0. The results were presented as means \pm SD, P Value less than 0.05 was considered to be significant.

\section{Results}

Plantar Test and Randall-Selitto method were used for thermal and mechanical withdrawal thresholds respectively.

\subsection{PlantarTest}

The thermal withdrawal threshold of the control group was, on average, $18.91 \pm 4.08$ seconds of the data collected prior to the injury. For the CCI group it was $12.42 \pm 4.82 \mathrm{sec}$ onds and $10.70 \pm 5.02$ seconds on the $7^{\text {th }}$ and $14^{\text {th }}$ days after the operation respectively. For the LLLT $660 \mathrm{~nm}$ group, the mean value was $18.34 \pm 4.29$ seconds and $19.88 \pm 3.13$ seconds on the $7^{\text {th }}$ day and $14^{\text {th }}$ days after the operation respectively. There was a significant difference between LLLT $660 \mathrm{~nm}$ and CCI groups on the $7^{\text {th }}$, and $14^{\text {th }}$ postoperative days $(\mathrm{P}<0.001)$. There was no significant difference between the $7^{\text {th }}$, and $14^{\text {th }}$ postoperative days of the LLLT $660 \mathrm{~nm}$ group and the control group (Figure 1 and 2)

Figure 1. Mean Values of the Thermal Withdrawal Threshold, 7 Days After the Operation

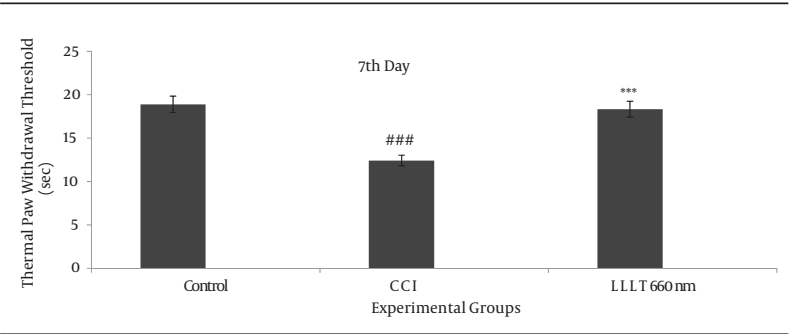

Mean values of the thermal withdrawal threshold obtained from the groups during the study period (before the operation (control), 7 days after the operation). Asterisks represent significant differences from CCl group $\left({ }^{* * *} P<0.001\right)$ and represent significant differences from Control group $(\# \# \# P<0.001)$

\subsection{Randall-Selitto Method}

The mean of mechanical withdrawal threshold of the control group was $19.18 \pm 4.66 \mathrm{~g}$ before the operation. For the CCI group were $10.17 \pm 4.18 \mathrm{~g}$ and $9.15 \pm 4.20 \mathrm{~g}$ on the $7^{\text {th }}$ and $14^{\text {th }}$ days after the operation respectively. For the LLLT $660 \mathrm{~nm}$ group, the mean values were $15.54 \pm 4.50 \mathrm{~g}$ and $14.36 \pm 5.43 \mathrm{~g}$ on the $7^{\text {th }}$ and $14^{\text {th }}$ days after the operation correspondingly. Statistical analysis indicated that the difference between control group and the CCI group on the 7 th, and $14^{\text {th }}$ postoperative days, was significant ( $P$
$<0.001$ ); also the difference between LLLT $660 \mathrm{~nm}$ group and the CCI group on the $7^{\text {th }}$, and $14^{\text {th }}$ postoperative days, was significant $(\mathrm{P}<0.001)$; and there was a significant difference between the $7^{\text {th }}$, and $14^{\text {th }}$ postoperative days of the LLLT 660nm group and the control group $(\mathrm{P}<$ $0.01, \mathrm{P}<0.001$, respectively) (Figure 3 and 4 ).

Figure 2. Mean values of the Thermal Withdrawal Threshold, 14 Days After the Operation

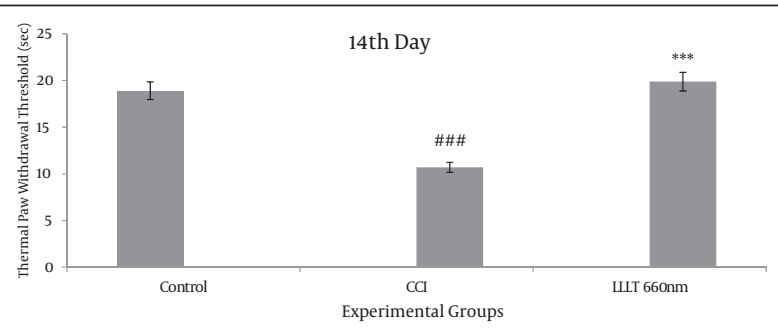

Mean values of the Thermal Withdrawal Threshold obtained from the groups during the study period (before the operation (control), 14 days after the operation). Asterisks represent significant differences from CCI group ( $\left.{ }^{* * *} P<0.001\right)$ and represent significant differences from Control group $(\# \# \# P<0.001)$

Figure 3. Mean values of the Mechanical Withdrawal Threshold, 7 Days After the Operation

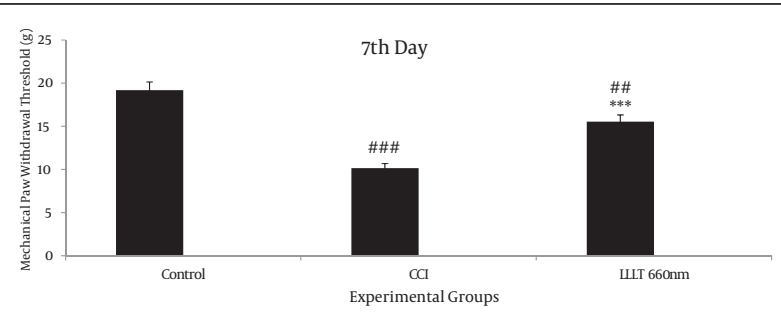

Mean values of the Mechanical Withdrawal Threshold obtained from the groups during the study period (before the operation (control), the 7 days after the operation). Asterisks represent significant differences from $\mathrm{CCl}$ group $\left({ }^{* *} P<0.001\right)$, and represent significant differences from Control group $(\# \# \# P<0.001 ; \# \# P<0.01)$.

Figure 4. Mean values of the Mechanical Withdrawal Threshold, 14 Days After the Operation

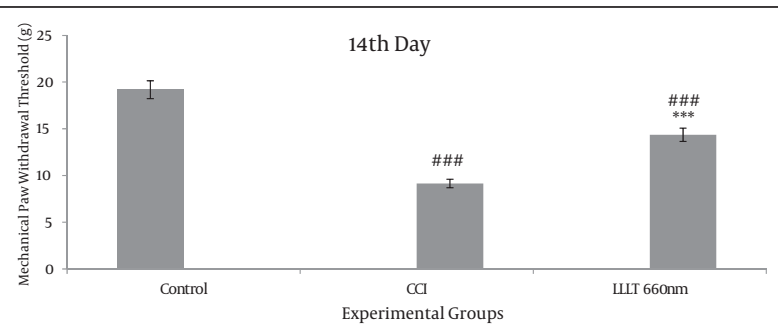

Mean values of the Mechanical Withdrawal Threshold obtained from the groups during the study period (before the operation (control), 14 days after the operation). Asterisks represent significant differences from CCl group $\left({ }^{* *} P<0.001\right)$, and represent significant differences from Control group (\#\#\# $P<0.001)$. 


\section{Discussion}

Our data significantly confirmed the therapeutic effects of LLLT on pain reduction in the CCI model; the wavelength of $660 \mathrm{~nm}$ was effective. In this section, we discuss the mechanisms of LLLT effectiveness on pain reduction. It is known that CCI induces an inflammatory condition which activates inflammatory cascade marked by the increase of proinflammatory cytokines such as IL-1 $\beta$, IL6 , and TNF- $\alpha$ which play important role in the etiology and continuation of neuropathic pain (25-28). In addition, prostaglandin E2 (PGE2) or prostaglandin I2 (PGI2) administration induces hyperalgesia and enhances the sensitivity of primary afferents to either mechanical or chemical stimulation (29-31). During the preinflammatory phase, the production of reactive oxygen species (ROS) increases, which in turn activates NF- $\mathrm{KB}(32,33)$. The activated NF- $\kappa B$ increases the expression of the iNOS and subsequent synthesis of $\mathrm{NO}(34,35)$. NO and its reactive nitrogen intermediates may destruct cells and tissues and play significant role in the pathology of certain inflammatory conditions (36). Regarding the LLLT effectiveness on pain reduction various mechanisms were postulated. Rabelo et al. reported the therapeutic effects of LLLT on wound healing of diabetic rat throughout reducing the inflammatory progress and reduction of inflammatory cell density (37). Same evidences are also reported for reducing of rat paw edema by red LLLT with wavelengths of $632.8 \mathrm{~nm}$ (He-Ne) and $650 \mathrm{~nm}(38,39)$. It is also shown that $660 \mathrm{~nm}$ and $684 \mathrm{~nm}$ from red diode lasers are effective in reducing edema (40). In another study on post traumatic muscular tissue repair, it was shown that LLLT reduced the inflammatory response, collagenesis, expression of iNOS, and the activation of NF- $\mathrm{KB}(41,42)$. It is reported that the expression of the proinflammatory gene such as IL-1 $\beta$ is suppressed by LLLT in human keratinocytes $(43,44)$. Aimbire et al. reported that LLLT $(650 \mathrm{~nm})$ reduced expression of TNF- $\alpha$, after acute immune complex lung injury, in rats (45). It is also shown that LLLT is able to inhibit production of PGE2 and decrease the mRNA levels of cyclooxygenase-2 (46). The role of ROS as a natural cytotoxic production of the normal metabolism of oxygen is reported. ROS has important roles in cell signaling, regulating nucleic acid synthesis, protein synthesis, enzyme activation, and cell cycle progression $(47,48)$. There are also reports on the effects of different wave lengths of LLLT. Wu et al. used transcranial LLLT with $36 \mathrm{~J} / \mathrm{cm}^{2}$ of a $665 \mathrm{~nm}, 810 \mathrm{~nm}$ and $980 \mathrm{~nm}$ laser four hours after traumatic brain injury. They reported the effectiveness of LLLT in improving the motor performance during the succeeding four weeks (49), and thus concluded that the absorption spectrum of the different chromophores located in the mitochondria and the cell membrane is important for LLLT therapeutic effects (49-51). Regarding photochemical effects of LLLT, the role of cytochrome c oxidase (complex IV mitochondrion) was also discussed (49). Cytochrome c oxidase is the photoreceptor in the red region of the spectrum which is responsible for activating the synthesis of ATP and consequently, better cell metabolism (52). The ability of the cell to have a greater energy source during the repair process might be the reason for the result in the group treated with laser $660 \mathrm{~nm}$. LLLT transmits energy at low levels and therefore does not release heat, sound, or vibrations. Other experiments using LLLT have shown that the immediate increase in heat of the target tissue is negligible (53). In addition to above mechanisms, it is also reported that wavelength of 660nm such as He-Ne laser leads to photo reactivation of cellular superoxide dismutase (54). Although some mechanisms for the effectiveness of LLLT are known or claimed, unknown ones remain to be studied. The significance of this study is to provide new ways in laser therapy for clinical trials to reduce certain types of pain in patients with peripheral nerve injuries.

\section{Acknowledgements}

The authors would like to thank the staff of Medical Basic Sciences Laboratory of faculty of Allied Medicine and Pain Laboratory, Faculty of Medicine of Iran University of Medical Sciences.

\section{Authors' Contribution}

Design, coordination, and writing: Dr. Seied Behnam Jameie; Research assistant: Masoome Masoomiepoor and Atousa Janzadeh; Counsaltant for behavioral Study: Dr. Farinaz Nasiri Nezhad; Surgery assistant: MAhdie Kerdari and Maryam Soleimani.

\section{Financial Disclosure}

This article is a result of a thesis from Azad Islamic University.

\section{Funding/Support}

This research work was supported by Islamic Azad University, Medical Basic Sciences Laboratory of Faculty of Allied Medicine, Pain Laboratory, Faculty of Medicine of Iran University of Medical Sciences.

\section{References}

1. Merskey H, Bogduk N. Part III: Pain terms, a current list with definitions and notes on usage. In: Merskey H, Bogduk N, editors. Classification of chronic pain: descriptions of chronic pain syndromes and definitions of pain terms. Seattle: IASP Press;1994. p. 209-14.

2. Wang LX, Wang ZJ. Animal and cellular models of chronic pain. Adv Drug Deliver Rev. 2003;55(8):949-65.

3. Woolf CJ, Mannion RJ. Neuropathic pain: aetiology, symptoms, mechanisms, and management. Lancet. 1999;353(9168):1959-64.

4. Zimmermann M. Pathobiology of neuropathic pain. Eur J Pharmacol. 2001;429(1-3):23-37.

5. Dubner R, editor. Neuronal plasticity and pain following peripheral tissue inflammation or nerve injury. Proceedings of the VIth World Congress on Pain.; 1991; Amsterdam: Elsevier. p. 263-76. 
6. Woolf $\mathrm{CJ}$. Windup and central sensitization are not equivalent. Pain. 1996;66(2-3):105-8.

7. Bennett GJ, Xie YK. A peripheral mononeuropathy in rat that produces disorders of pain sensation like those seen in man. Pain. 1988;33(1):87-107.

8. Bennett GJ, Chung JM, Seltzer Z. Models of neuropathic pain in the rat. Curr Protoc Pharmacol. 2003:5.32.1-5.32.16.

9. D'amour FE, Smith DL. A method for determining loss of pain sensation.J Pharmacol Exp Ther. 1941;72(1):74-9.

10. Hargreaves K, Dubner R, Brown F, Flores C, Joris J. A new and sensitive method for measuring thermal nociception in cutaneous hyperalgesia. Pain. 1988;32(1):77-88.

11. Espejo EF, Mir D. Structure of the rat's behaviour in the hot plate test. Behav Brain Res. 1993;56(2):171-6.

12. Woolfe G, Macdonald AD. The evaluation of the analgesic action of pethidine hydrochloride (demerol). J Pharmacol Exp. 1944;80:300-7.

13. Chaplan SR, Bach FW, Pogrel JW, Chung JM, Yaksh TL. Quantitative assessment of tactile allodynia in the rat paw.J Neurosci Methods. 1994;53(1):55-63.

14. Dubner R. Methods of assessing pain in animals. In: Wall PD, Melzack R, editors. Pain. Edinburgh: Churchville Livingstone; 1989. p. 247-56.

15. Mendonca AC, Barbieri CH, Mazzer N. Directly applied low intensity direct electric current enhances peripheral nerve regeneration in rats. J Neurosci Methods. 2003;129(2):183-90.

16. Huang YY, Chen AC, Carroll JD, Hamblin MR. Biphasic dose response in low level light therapy. Dose Response. 2009;7(4):35883.

17. Ohshiro T, Calderhead RG, Walker JB. Low level laser therapy: a practical introduction. New York: Wiley; 1988.

18. Schindl A, Schindl M, Schindl L, Jurecka W, Honigsmann H, Breier F. Increased dermal angiogenesis after low-intensity laser therapy for a chronic radiation ulcer determined by a video measuring system. J Am Acad Dermatol.1999;40(3):481-4.

19. dos Reis FA, Belchior AC, de Carvalho Pde T, da Silva BA, Pereira DM, Silva IS, et al. Effect of laser therapy (660 nm) on recovery of the sciatic nerve in rats after injury through neurotmesis followed by epineural anastomosis. Lasers Med Sci. 2009;24(5):741-7.

20. Belchior AC, dos Reis FA, Nicolau RA, Silva IS, Perreira DM, de Carvalho Pde T. Influence of laser ( $660 \mathrm{~nm}$ ) on functional recovery of the sciatic nerve in rats following crushing lesion. Lasers Med Sci. 2009;24(6):893-9.

21. Barbosa RI, Marcolino AM, de Jesus Guirro RR, Mazzer N, Barbieri $\mathrm{CH}$, de Cassia Registro Fonseca M. Comparative effects of wavelengths of low-power laser in regeneration of sciatic nerve in rats following crushing lesion. Lasers Med Sci. 2010;25(3):423-30.

22. Hsieh YL, Chou LW, Chang PL, Yang CC, Kao MJ, Hong CZ. Low-leve laser therapy alleviates neuropathic pain and promotes function recovery in rats with chronic constriction injury: possible involvements in hypoxia-inducible factor 1alpha (HIF-1alpha). $J$ Comp Neurol. 2012;520(13):2903-16.

23. Bertolini GR, Artifon EL, Silva TS, Cunha DM, Vigo PR. Low-level laser therapy, at $830 \mathrm{~nm}$, for pain reduction in experimental model of rats with sciatica. Arq Neuropsiquiatr. 2011;69(2B):356-9.

24. Randall LO, Selitto JJ. A method for measurement of analgesic activity on inflamed tissue. Arch Int Pharmacodyn Ther. 1957;111(4):409-19.

25. Cui JG, Holmin S, Mathiesen T, Meyerson BA, Linderoth B. Possible role of inflammatory mediators in tactile hypersensitivity in rat models of mononeuropathy. Pain. 2000;88(3):239-48.

26. Leung L, Cahill CM. TNF-alpha and neuropathic pain-a review. J Neuroinflammation. 2010;7:27.

27. Martucci C, Trovato AE, Costa B, Borsani E, Franchi S, Magnaghi $\mathrm{V}$, et al. The purinergic antagonist PPADS reduces pain related behaviours and interleukin-1 beta, interleukin-6, iNOS and nNOS overproduction in central and peripheral nervous system after peripheral neuropathy in mice. Pain. 2008;137(1):81-95.

28. Sommer C, Kress M. Recent findings on how proinflammatory cytokines cause pain: peripheral mechanisms in inflammatory and neuropathic hyperalgesia. Neurosci Lett. 2004;361(1-3):184-7.
29. Devor M, White DM, Goetzl EJ, Levine JD. Eicosanoids, but not tachykinins, excite C-fiber endings in rat sciatic nerve-end neuromas. Neuroreport. 1992;3(1):21-4.

30. Higgs EA, Moncada S, Vane JR. Inflammatory effects of prostacyclin (PGI2) and 6-oxo-PGF1alpha in the rat paw. Prostaglandins. 1978;16(2):153-62.

31. Schepelmann K, Messlinger K, Schaible HG, Schmidt RF. Inflammatory mediators and nociception in the joint: excitation and sensitization of slowly conducting afferent fibers of cat's knee by prostaglandin I2. Neuroscience. 1992;50(1):237-47.

32. Cuzzocrea S, Thiemermann C, Salvemini D. Potential therapeutic effect of antioxidant therapy in shock and inflammation. Cur Med Chem. 2004;11(9):1147-62.

33. Torres SH, De Sanctis JB, de L Briceno M, Hernandez N, Finol HJ Inflammation and nitric oxide production in skeletal muscle of type 2 diabetic patients. J Endocrinol. 2004;181(3):419-27.

34. Adams V, Nehrhoff B, Spate U, Linke A, Schulze PC, Baur A, et al. Induction of iNOS expression in skeletal muscle by IL-1beta and NFkappaB activation: an in vitro and in vivo study. Cardiovasc Res. 2002;54(1):95-104

35. Gomez-Cabrera MC, Borras C, Pallardo FV, Sastre J, Ji LL, Vina J. Decreasing xanthine oxidase-mediated oxidative stress prevents useful cellular adaptations to exercise in rats. J Physiol. 2005;567(Pt 1):113-20.

36. Gilad E, Wong HR, Zingarelli B, Virag L, O'Connor M, Salzman AL, et al. Melatonin inhibits expression of the inducible isoform of nitric oxide synthase in murine macrophages: role of inhibition of NFkappaB activation. FASEB J.1998;12(9):685-93.

37. Rabelo SB, Villaverde AB, Nicolau R, Salgado MC, Melo Mda S, Pa checo MT. Comparison between wound healing in induced diabetic and nondiabetic rats after low-level laser therapy. Photomed Laser Surg. 2006;24(4):474-9.

38. Albertini R, Aimbire FS, Correa FI, Ribeiro W, Cogo JC, Antunes $\mathrm{E}$, et al. Effects of different protocol doses of low power galliumaluminum-arsenate (Ga-Al-As) laser radiation $(650 \mathrm{~nm})$ on carrageenan induced rat paw ooedema. J Photochem Photobiol B. 2004;74(2-3):101-7.

39. Ferreira DM, Zangaro RA, Villaverde AB, Cury Y, Frigo L, Picolo G, et al. Analgesic effect of $\mathrm{He}-\mathrm{Ne}(632.8 \mathrm{~nm})$ low-level laser therapy on acute inflammatory pain. Photomed Laser Surg. 2005;23(2):177-81.

40. Albertini R, Villaverde AB, Aimbire F, Salgado MA, Bjordal JM, Alves LP, et al. Anti-inflammatory effects of low-level laser therapy (LLLT) with two different red wavelengths $(660 \mathrm{~nm}$ and 684 $\mathrm{nm}$ ) in carrageenan-induced rat paw edema.J Photochem Photobiol B. 2007;89(1):50-5.

41. Moriyama Y, Moriyama EH, Blackmore K, Akens MK, Lilge L. In vivo study of the inflammatory modulating effects of low-leve laser therapy on iNOS expression using bioluminescence imaging. Photochem Photobiol. 2005;81(6):1351-5.

42. Rizzi CF, Mauriz IL, Freitas Correa DS, Moreira AJ, Zettler CG, Filippin LI, et al. Effects of low-level laser therapy (LLLT) on the nuclear factor (NF)-kappaB signaling pathway in traumatized muscle. Lasers Surg Med. 2006;38(7):704-13.

43. Gavish L, Asher Y, Becker Y, Kleinman Y. Low level laser irradiation stimulates mitochondrial membrane potential and disperses subnuclear promyelocytic leukemia protein. Lasers Surg Med. 2004;35(5):369-76.

44. Gavish L, Perez L, Gertz SD. Low-level laser irradiation modulates matrix metalloproteinase activity and gene expression in porcine aortic smooth muscle cells. Lasers Surg Med. 2006;38(8):77986.

45. Aimbire F, Albertini R, Pacheco MT, Castro-Faria-Neto HC, Leonardo PS, Iversen VV, et al. Low-level laser therapy induces dosedependent reduction of TNFalpha levels in acute inflammation. Photomed Laser Surg. 2006;24(1):33-7.

46. Sakurai Y, Yamaguchi M, Abiko Y. Inhibitory effect of low-level laser irradiation on LPS-stimulated prostaglandin E2 production and cyclooxygenase-2 in human gingival fibroblasts. Eur J Ora Sci. 2000;108(1):29-34.

47. Brondon P, Stadler I, Lanzafame RJ. A study of the effects of phototherapy dose interval on photobiomodulation of cell cultures. 
Lasers Surg Med. 2005;36(5):409-13.

48. Storz P. Mitochondrial ROS-radical detoxification, mediated by protein kinase D. Trends Cell Biol. 2007;17(1):13-8.

49. Wu Q, Huang YY, Dhital S, Hamblin MR, Anders JJ, Waynant RW, editors. Low level laser therapy for traumatic brain injury. Mechanisms for Low-Light Therapy V. Proc SPIE; 2010.

50. Amat A, Rigau J, Waynant RW, Ilev IK, Anders JJ. The electric field induced by light can explain cellular responses to electromagnetic energy: a hypothesis of mechanism.J Photochem Photobiol B. 2006;82(2):152-60.

51. Vladimirov Y. Efferent medicine. Chikin S, editor. Moscow: Insti- tute of Biomedical Chemistry, Russian Academy of Medical Sciences; 1994. p. 51-66.

52. Manteifel VM, Karu TI. [Structure of mitochondria and activity of their respiratory chain in subsequent generations of yeast cells exposed to He-Ne laser light]. Izv Akad Nauk Ser Biol. 2005;(6):672-83.

53. Hrnjak M, Kuljic-Kapulica N, Budisin A, Giser A. Stimulatory effect of low-power density He-Ne laser radiation on human fibroblasts in vitro. Vojnosanit Pregl. 1995;52(6):539-46.

54. Romm AR, Sherstnev MP, Volkov VV, Vladimirov Iu A. [Action of laser radiation on the peroxide chemiluminescence of wound exudate]. Biull Eksp Biol Med.1986;102(10):426-8. 